\title{
Activation of transient receptor potential vanilloid 1 protects the heart against apoptosis in ischemia/reperfusion injury through upregulating the PI3K/Akt signaling pathway
}

\author{
XIAO-XUE JIANG ${ }^{1}$, GUAN-YU LIU ${ }^{2}$, HAN LEI ${ }^{1}$, ZUO-LING LI ${ }^{1}$, QING-PING FENG ${ }^{3}$ and WEI HUANG ${ }^{1}$ \\ ${ }^{1}$ Cardiovascular Laboratory, Department of Cardiology; ${ }^{2}$ Department of Urology, The First Affiliated Hospital of \\ Chongqing Medical University, Chongqing 400016, P.R. China; ${ }^{3}$ Department of Physiology and Pharmacology, \\ University of Western Ontario, London, ON N6A-5C1, Canada
}

Received October 23, 2016; Accepted December 13, 2017

DOI: 10.3892/ijmm.2017.3338

\begin{abstract}
Transient receptor potential vanilloid 1 (TRPV1) is a nonselective cation channel and a molecular integrator of noxious stimuli. TRPV1 activation confers cardiac protection against ischemia/reperfusion (I/R) injury. The present study aimed to investigate whether the cardioprotective effects of TRPV1 were associated with the inhibition of apoptosis via the phosphatidylinositol 3-kinase (PI3K)/protein kinase B (Akt) and extracellular signal-regulated protein kinase 1/2 (ERK1/2) signaling pathways. Briefly, the hearts of TRPV1 knockout (TRPV1 ${ }^{-1}$ ) or wild-type (WT) mice were isolated and subjected to $30 \mathrm{~min}$ of ischemia followed by $60 \mathrm{~min}$ of reperfusion in a Langendorff apparatus in the presence or absence of the PI3K inhibitor, LY294002. At the end of reperfusion, infarct size was measured using 2,3,5-triphenyltetrazolium chloride staining and myocardial apoptosis was assessed by terminal deoxynucleotidyl transferase-mediated dUTP nick-end labeling (TUNEL) staining. The expression levels of B-cell lymphoma 2 (Bcl-2), Bcl-2-associated X protein (Bax), and phosphorylated Akt and ERK1/2 were determined by western blot analysis. There was a significant increase in the
\end{abstract}

Correspondence to: Dr Wei Huang, Cardiovascular Laboratory, Department of Cardiology, The First Affiliated Hospital of Chongqing Medical University, 1 Youyi Road, Yuzhong, Chongqing 400016, P.R. China

E-mail: weihuangcq@gmail.com

Abbreviations: Bax, B-cell lymphoma 2-associated X protein; ERK1/2, extracellular signal-regulated protein kinase 1/2; PI3K/Akt, phosphatidylinositol 3-kinase/protein kinase B; TRPV1, transient receptor potential vanilloid 1; TTC, 2,3,5-triphenyl tetrazolium chloride; TUNEL, terminal deoxynucleotidyl transferase-mediated dUTP nick-end labeling

Key words: transient receptor potential vanilloid channel, cardioprotection, phosphatidylinositol 3-kinase/Akt signaling pathway, myocardial ischemia/reperfusion, apoptosis extent of infarction and the percentage of TUNEL-positive cells, and a decrease in the Bcl-2/Bax ratio, and Akt and ERK1/2 phosphorylation in TRPV1 ${ }^{-/}$hearts. In addition, treatment with LY294002 increased infarct size and the percentage of TUNEL-positive cells, and reduced Bcl-2/Bax expression and Akt phosphorylation in WT hearts, but not in TRPV1 ${ }^{-1-}$ hearts, following I/R. Taken together, these data suggested that TRPV1 serves a protective role against myocardial apoptosis during I/R via the PI3K/Akt signaling pathway. In conclusion, activating TRPV1 may be considered a potential approach to protect the heart against I/R injury.

\section{Introduction}

Ischemic heart disease is a leading cause of morbidity and mortality $(1,2)$. Reperfusion of coronary arteries in response to thrombolytic treatment or percutaneous coronary intervention is crucial for reducing ischemia-induced heart damage (3-5). However, reperfusion may induce additional myocardial injury, including cardiomyocyte death and loss of cardiac function; this is known as myocardial ischemia/reperfusion (I/R) injury (6-8). The cellular mechanisms underlying I/R injury remain to be completely elucidated. Increasing evidence has suggested that ischemia initiates myocardial apoptosis, which is amplified by reperfusion, thus contributing to cardiac cell death $(9,10)$. Conversely, suppressing apoptotic processes can minimize I/R-induced cardiac damage (11).

Transient receptor potential vanilloid 1 (TRPV1) is a ligand-gated nonselective cation channel, which is primarily expressed in sensory nerves that innervate cardiovascular tissues, including the heart and blood vessels $(12,13)$. TRPV1 has been considered to act as a molecular integrator of numerous chemical and physical mediators, including noxious heat, low pH, capsaicin and lipid metabolites (14-16). TRPV1 expressed in the cardiac sensory nerves, which conduct angina pain signals $(17,18)$, may function as a molecular sensor for the detection of tissue ischemia and the modulation of cardiac function (12). Pharmacological studies have suggested that activation of TRPV1 with exogenous agonists protects the heart from I/R injury $(19,20)$, whereas TRPV1 gene deletion may impair cardiac recovery following I/R (21). Furthermore, 
activation of TRPV1 inhibits hypoxia/reoxygenation-induced apoptosis in rat hippocampal neurons via activation of the phosphatidylinositol 3-kinase/protein kinase B (PI3K/Akt) and extracellular signal-regulated protein kinase 1/2 (ERK1/2) signaling pathways (22), which are key regulators of cell growth and survival $(23,24)$. During I/R, both signaling pathways are activated and confer cardioprotective effects through the recruitment of downstream anti-apoptotic molecules (25); however, the role of TRPV1 in myocardial apoptosis in response to I/R injury remains to be fully characterized. Furthermore, it is currently unknown whether the PI3K/Akt and ERK1/2 signaling pathways are involved in TRPV1-mediated myocardial apoptosis in I/R. The present study aimed to determine the effects of TRPV1 activation on myocardial apoptosis in response to I/R injury and explored the downstream signaling mechanism of TRPV1 activation.

\section{Materials and methods}

Animals and reagents. Male TRPV1 knockout (TRPV1 ${ }^{-/}$) and wild-type (WT) C57BL/6J mice ( $\mathrm{n}=54$ each; weight, 25-30 g; age, 10-12 weeks) were provided by the Experimental Animal Center of Chongqing Medical University (Chongqing, China) and were maintained under specific pathogen-free conditions (temperature, $22^{\circ} \mathrm{C}$; humidity, $60 \%$ ), with a 12 -h light/dark cycle and with free access to food and water. All surgical procedures performed on mice were conducted under sodium pentobarbital anesthesia $[50 \mathrm{mg} / \mathrm{kg}$, intraperitoneal (IP) injection], and all efforts were made to minimize their suffering. The present study was approved by the Ethics Committee of Chongqing Medical University. The mice were treated in accordance with the recommendations listed in the Guide for the Care and Use of Laboratory Animals of the National Institutes of Health (NIH) (26).

LY294002 (a PI3K inhibitor) and 2,3,5-triphenyl tetrazolium chloride (TTC) were purchased from Sigma-Aldrich (Merck KGaA, Darmstadt, Germany); antibodies against phosphorylated (p)-Akt (Ser473; cat. no. 9271), Akt (cat. no. 9272), p-ERK1/2 (Thr202/Thr204; cat. no. 4370), ERK1/2 (cat. no. 9102), B-cell lymphoma-2 (Bcl-2; cat. no. 2870) and Bcl-2-associated X protein (Bax; cat. no. 14796) were purchased from Cell Signaling Technology, Inc. (Danvers, MA, USA). Anti-GAPDH antibody (cat. no. AG019) and the bicinchoninic acid (BCA) protein assay kit were purchased from Beyotime Institute of Biotechnology (Haimen, China). The terminal deoxynucleotidyl transferase-mediated dUTP nick-end labeling (TUNEL) reaction mixture was purchased from Roche Diagnostics (Laval, QC, Canada).

Langendorff heart preparation. Mice were treated with heparin $(500 \mathrm{U} / \mathrm{kg}, \mathrm{IP})$ and anesthetized with pentobarbital sodium $(50 \mathrm{mg} / \mathrm{kg}, \mathrm{IP})$ prior to thoracotomy. The hearts were rapidly excised, placed into ice-cold Krebs-Henseleit (K-H) buffer (composition in mM: $\mathrm{NaCl} 118, \mathrm{KCl} 4.7, \mathrm{MgSO}_{4} 1.2$, $\mathrm{KH}_{2} \mathrm{PO}_{4} 1.2, \mathrm{CaCl}_{2} 2.5, \mathrm{NaHCO}_{3} 25, \mathrm{Na}-\mathrm{EDTA} 0.5$ and glucose 11) and perfused in a Langendorff apparatus within $2 \mathrm{~min}$ under a constant pressure of $80 \mathrm{mmHg}$. The perfusion fluid was oxygenated with a mixture of $95 \% \mathrm{O}_{2}$ and $5 \% \mathrm{CO}_{2}$, and was maintained at $\mathrm{pH}$ 7.4. In addition, temperature of the $\mathrm{K}-\mathrm{H}$ buffer was maintained at $37^{\circ} \mathrm{C}$ throughout the experi- ment. A fluid-filled balloon connected to a pressure transducer was inserted into the left ventricle (LV) via the mitral valve to monitor LV pressure. The volume of the balloon was adjusted to maintain a stable $\mathrm{LV}$ end-diastolic pressure of $5-8 \mathrm{mmHg}$ during initial equilibration.

Experimental protocol. The isolated mouse hearts were randomly divided into the following six groups ( $\mathrm{n}=9 /$ group): i) WT Sham group; ii) TRPV1 ${ }^{-/}$Sham group; iii) WT I/R group; iv) TRPV1 ${ }^{-/}$I/R group; v) WT I/R + LY294002 group; and vi) $\mathrm{TRPV}^{-/-} \mathrm{I} / \mathrm{R}+\mathrm{LY} 294002$ group. To induce I/R, the perfused hearts were stabilized for $30 \mathrm{~min}$ and subjected to global normothermic $\left(37^{\circ} \mathrm{C}\right)$ ischemia (no flow) for $30 \mathrm{~min}$, followed by $60 \mathrm{~min}$ of reperfusion. Conversely, hearts in the sham groups were perfused with K-H solution continuously until the end of the experiment. Hearts in the LY294002 treatment group were perfused for 10 min with LY294002 $(50 \mu \mathrm{M})$ in K-H buffer prior to induction of global ischemia, the hearts were then subjected to global ischemia followed by reperfusion without LY294002. LY294002 was initially dissolved in dimethyl sulfoxide and then in K-H buffer to reach a final concentration of $50 \mu \mathrm{M}$. The concentration of LY294002 used in the present study has been reported to specifically abolish PI3K activity and inhibit Akt phosphorylation, but not the phosphorylation of other protein kinases, including phosphatidylinositol 4-kinase, protein kinase $\mathrm{C}$, mitogen-activated protein kinase or c-Src (27). The experimental protocol is presented in Fig. 1.

Determination of myocardial infarct size. At the end of reperfusion, the hearts were frozen at $-20^{\circ} \mathrm{C}$ for $15 \mathrm{~min}$ and cut into five pieces along the longitudinal heart axis. Heart sections were incubated for $10 \mathrm{~min}$ in $1 \% \mathrm{TTC}$ at $37^{\circ} \mathrm{C}$ in the dark. Subsequently, the sections were soaked in $4 \%$ paraformaldehyde in phosphate buffer overnight at $4^{\circ} \mathrm{C}$ to enhance the contrast of the stain. Viable myocardium exhibited red staining, whereas the infarcted area exhibited white staining. Each image was digitally photographed and the infarct size was analyzed using ImageJ software version $1.49 \mathrm{v}(\mathrm{NIH}$, Bethesda, MD, USA). The infarct size was expressed as a percentage of the total area of the heart.

Measurement of myocardial cell apoptosis. For tissue TUNEL staining, the heart samples were fixed in $4 \%$ paraformaldehyde at $25^{\circ} \mathrm{C}$ for $24 \mathrm{~h}$, embedded in paraffin and cut into transverse sections $(5 \mu \mathrm{m})$. Myocardial apoptosis was assessed using a TUNEL staining kit according to the manufacturer's protocol. The numbers of TUNEL-positive myocyte nuclei and total myocyte nuclei were counted in 10 different fields for each stained section at high magnification (objective, $x 400)$. The number of TUNEL-positive nuclei (brown staining) was calculated using ImageJ software (NIH) according to the following formula: Percentage of TUNEL-positive myocyte nuclei $=$ TUNEL-positive myocyte nuclei/total myocyte nuclei $\mathrm{x} 100 \%$.

Western blot analysis. Total proteins were extracted from mouse heart tissues and protein concentrations were assessed using a BCA protein assay kit. The mouse heart tissues were homogenized using radioimmunoprecipitation lysis buffer 


\begin{tabular}{|c|c|c|c|c|}
\hline Time & $20 \mathrm{~min}$ & $10 \mathrm{~min} \downarrow$ & $30 \mathrm{~min}$ & $60 \mathrm{~min}$ \\
\hline WT + Sham & \multicolumn{4}{|c|}{ Perfusion } \\
\hline TRPV1*+ Sham & \multicolumn{4}{|c|}{ Perfusion } \\
\hline$W T+I / R$ & \multicolumn{2}{|c|}{ Baseline } & Ischemia & Reperfusion \\
\hline $\mathrm{TRPV}^{\star *}+\mathrm{I} / \mathrm{R}$ & \multicolumn{2}{|c|}{ Baseline } & Ischemia & Reperfusion \\
\hline$W T+L Y$ & Baseline & LY & Ischemia & Reperfusion \\
\hline TRPV1 ${ }^{*}+$ LY & Baseline & LY & Ischemia & Reperfusion \\
\hline
\end{tabular}

Figure 1. Experimental protocol. Isolated hearts from WT and TRPV1 ${ }^{-/}$mice were subjected to 30 min no-flow global ischemia followed by 60 min of reperfusion. The sham-operated group underwent time-matched perfusion without ischemia. LY (50 $\mu \mathrm{M})$ was perfused for 10 min prior to ischemia. I/R, ischemia/reperfusion; LY, LY294002; TRPV1 ${ }^{-/}$, transient receptor potential vanilloid 1 knockout; WT, wild-type.

(RIPA; Beyotime Institue of Biotechnology) and then centrifuged at $4^{\circ} \mathrm{C}$. Equal amounts of protein $(4 \mu \mathrm{g} / \mu \mathrm{l})$ were separated by $10-12 \%$ SDS-PAGE and were transferred onto polyvinylidene fluoride (PVDF) membranes (Bio-Rad Laboratories, Inc., Hercules, CA, USA). The PVDF membranes were blocked in 5\% non-fat milk in Tris-buffered saline containing $0.05 \%$ Tween-20 for $2 \mathrm{~h}$ at room temperature, and were then incubated overnight at $4{ }^{\circ} \mathrm{C}$ with primary antibodies against GAPDH (1:1,000 dilution), p-Akt (Ser473) (1:1,000 dilution), Akt (1:1,000 dilution), p-ERK1/2 (Thr202/Thr204) (1:2,000 dilution), ERK1/2 (1:1,000 dilution), Bcl-2 (1:1,000 dilution) and $\operatorname{Bax}$ (1:1,000 dilution). Subsequently, the membranes were incubated with horseradish peroxidase-conjugated secondary antibodies (1:5,000 dilution; ZB-5305; Beijing Zhongshan Golden Bridge Biotechnology Co., Beijing, China) for $2 \mathrm{~h}$ at room temperature. The immunoreactive proteins were visualized using an enhanced chemiluminescence detection system (Pierce; Thermo Fisher Scientific Inc., Waltham, MA, USA). The band density was analyzed by ImageJ software (NIH).

Statistical analysis. SPSS 17.0 statistical software (SPSS, Inc., Chicago, IL, USA) was used for all statistical analyses. Data are expressed as the means \pm standard deviation. Significance was determined using either an unpaired Student's t-test (differences in TUNEL-positive cells and infarct size in $\mathrm{TRPV}^{-/}$hearts compared with in WT hearts) or one-way analysis of variance followed by the Tukey-Kramer multiple comparison test. $\mathrm{P}<0.05$ was considered to indicate a statistically significant difference.

\section{Results}

Myocardial apoptosis is increased in TRPVI ${ }^{-/}$hearts following $I / R$. To investigate the role of TRPV1 in apoptosis, WT and TRPV ${ }^{-/}$hearts were subjected to I/R, and myocardial apoptosis was detected using TUNEL staining (Fig. 2). The percentage of TUNEL-positive cardiomyocytes was markedly increased in the TRPV1 $1^{-/}$and WT hearts following I/R compared with in the respective sham control groups $(\mathrm{P}<0.01)$. Furthermore, the percentage of TUNEL-positive cardiomyocytes in TRPV1 ${ }^{-1-}$ hearts subjected to I/R was significantly greater than in WT hearts $(25.10+1.03$ vs. $18.20+2.79 \%$; $\mathrm{P}<0.01)$. In addition, treatment with the PI3K inhibitor LY294002 prior to I/R, increased myocardial apoptosis in WT $(\mathrm{P}<0.01)$ but not in $\mathrm{TRPV}^{-/}$hearts (P>0.05) (Fig. 2).

Infarct size is larger in TRPVI $1^{-1}$ hearts following I/R. Myocardial infarct size was assessed using TTC staining(Fig.3). Myocardial infarct size was markedly increased in the TRPV1 ${ }^{-/-}$and WT groups following I/R compared with in the corresponding sham groups $(\mathrm{P}<0.01)$ (data not shown). Notably, infarct size in TRPV ${ }^{-/-}$hearts was markedly increased compared with in the WT hearts $(49.58+4.83$ vs. $26.32+4.57 \%$; $\mathrm{P}<0.01)$. In addition, treatment with LY294002 significantly increased infarct size in WT $(\mathrm{P}<0.01)$ but not in TRPV1 ${ }^{-/}$hearts $(\mathrm{P}>0.05)$ (Fig. 3).

PI3K/Akt signaling is involved in the anti-apoptotic effects of TRPV1. The PI3K/Akt and ERK1/2 survival signaling pathways serve key roles in protecting cardiomyocytes from apoptosis during I/R injury. To determine the downstream signaling pathway associated with the effects of TRPV1, Akt and ERK1/2 phosphorylation was detected in heart samples exposed to I/R (Fig. 4). Myocardial I/R significantly increased p-Akt and p-ERK1/2 expression in TRPV1 ${ }^{-/-}$and WT hearts $(\mathrm{P}<0.05)$, without any significant changes in total ERK1/2 and Akt protein levels. The ratios of $\mathrm{p}$-AKT/AKT and p-ERK1/2/ERK1/2 were significantly higher following I/R in WT hearts compared with in TRPV1 ${ }^{-/}$hearts $(\mathrm{P}<0.01)$; however, these ratios were decreased following LY294002 treatment $(\mathrm{P}<0.01)$ (Fig. 4). These results suggested that the PI3K/Akt signaling pathway may be involved in the beneficial effects of TRPV1 during I/R injury.

TRPV1 activation increases $B c l-2 / B a x$ ratio by activating the PI3K-Akt signaling pathway. To further examine the 
A
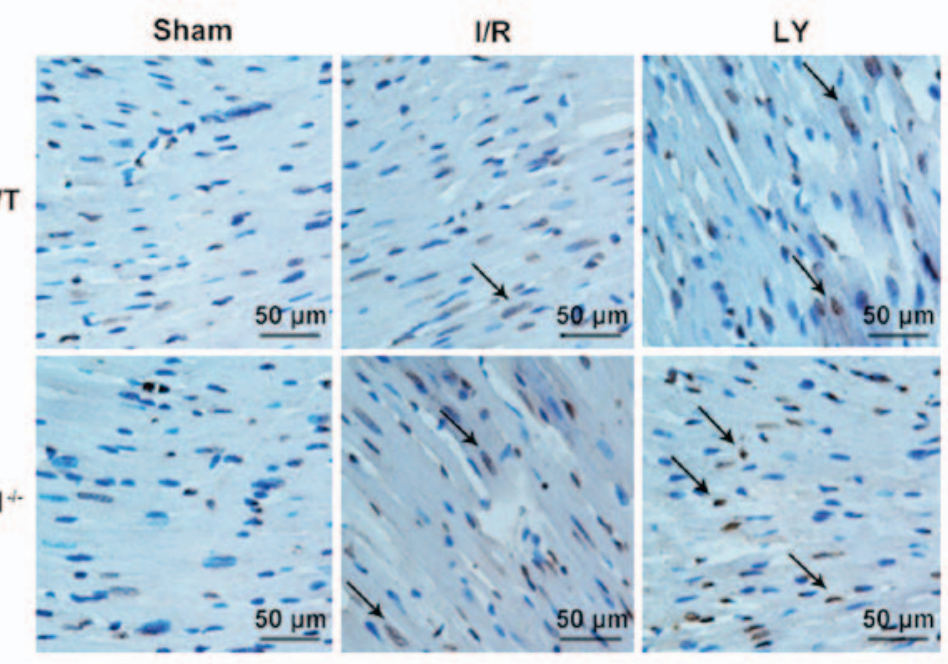

B

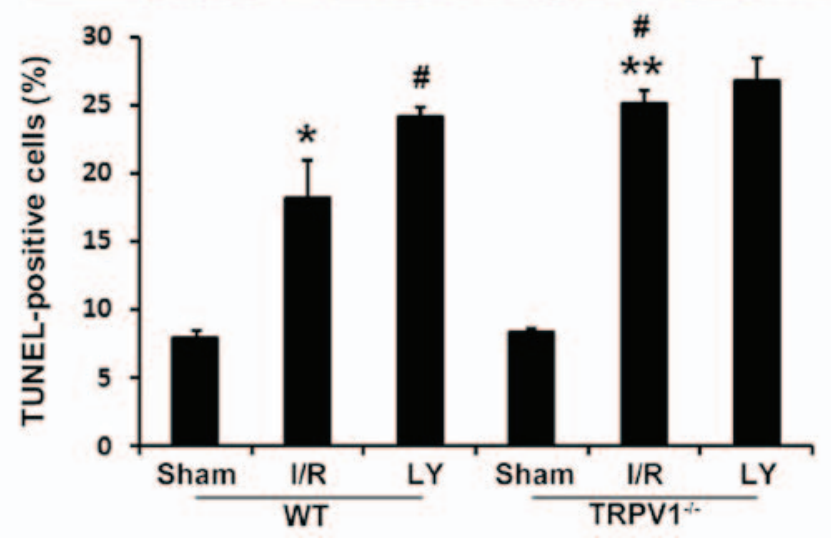

Figure 2. I/R injury induced myocardial apoptosis, as determined by TUNEL staining. (A) Representative photomicrographs of TUNEL staining (scale bars, $50 \mu \mathrm{m}$ ). (B) Bar graph showing the quantified results of TUNEL staining analysis. TUNEL-positive cells are shown at $\mathrm{x} 400$ magnification. Black arrows indicate TUNEL-positive cells. Data are presented as the means \pm standard deviation of three independent experiments. "P $<0.01$ vs. the WT Sham group; ${ }^{* *} \mathrm{P}<0.01$ vs. the TRPV1 ${ }^{-/}$Sham group; ${ }^{*} \mathrm{P}<0.01$ vs. the WT I/R group. I/R, ischemia/reperfusion; LY, LY294002; TRPV1 $1^{-/}$, transient receptor potential vanilloid 1 knockout; TUNEL, terminal deoxynucleotidyl transferase-mediated dUTP nick-end labeling; WT, wild-type.
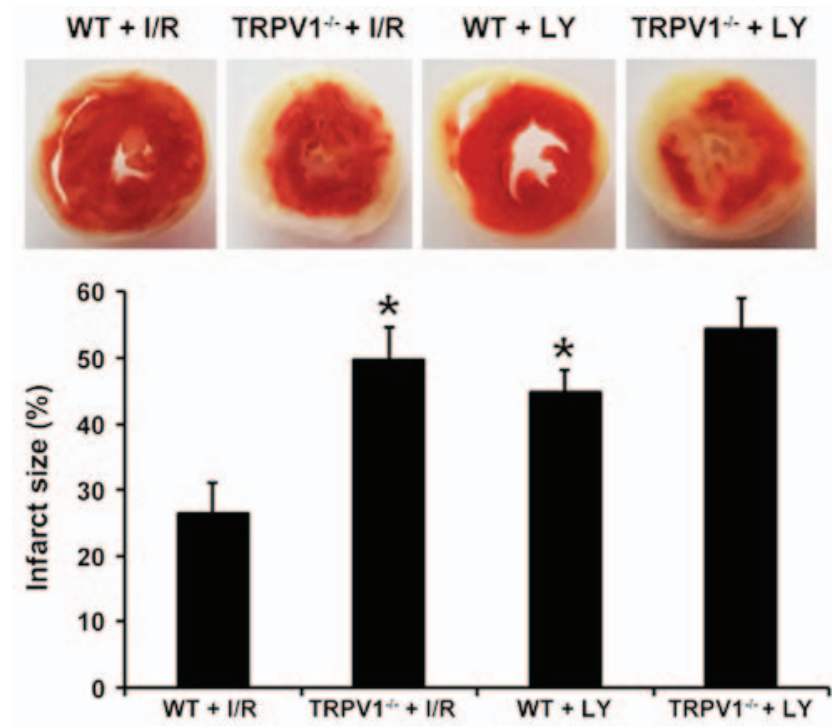

Figure 3. Infarct size, as measured by TTC staining following $30 \mathrm{~min}$ of global ischaemia and $60 \mathrm{~min}$ of reperfusion. Upper panels are the representative cross-sections of TTC-stained hearts. White staining indicates the infarcted region, and red staining indicates viable myocardium. Data are presented as the means \pm standard deviation of three independent experiments. ${ }^{*} \mathrm{P}<0.01$ vs. the WT I/R group. I/R, ischemia/reperfusion; LY, LY294002 $\mathrm{TRPV}^{-/}$, transient receptor potential vanilloid 1 knockout; TTC, I/R, ischemia/reperfusion; WT, wild-type. mechanism of apoptosis, the protein expression levels of Bax and Bcl-2 were determined (Fig. 5). Bcl-2 and Bax have major roles in determining cell survival or death in response to apoptotic stimuli $(28,29)$. The present study demonstrated that I/R resulted in a significant decrease in Bcl-2/Bax protein ratio compared with in the sham group in TRPV1-- and WT hearts $(\mathrm{P}<0.05)$. In addition, the ratio of $\mathrm{Bcl}-2 / \mathrm{Bax}$ was lower in the of TRPV $1^{-1}$ hearts compared with in WT hearts following I/R $(\mathrm{P}<0.01)$. Furthermore, treatment with LY294002 markedly decreased $\mathrm{Bcl}-2 / \mathrm{Bax}$ ratio in WT hearts $(\mathrm{P}<0.01)$ but not in TRPV1 ${ }^{-1}$ hearts (Fig. 5).

\section{Discussion}

The present study demonstrated that TRPV1 gene knockdown significantly increased myocardial apoptosis and infarction during I/R. In addition, treatment with the PI3K inhibitor LY294002 increased infarct size and number of TUNEL-positive cardiomyocytes in WT but not in TRPV $1^{-1-}$ hearts. These results indicated that TRPV1 may protect the heart against I/R injury, possibly through its anti-apoptotic effects via activating the PI3K/Akt signaling pathway.

The importance of the TRPV1 channel in regulating heart function has recently been highlighted. TRPV1 can 
A
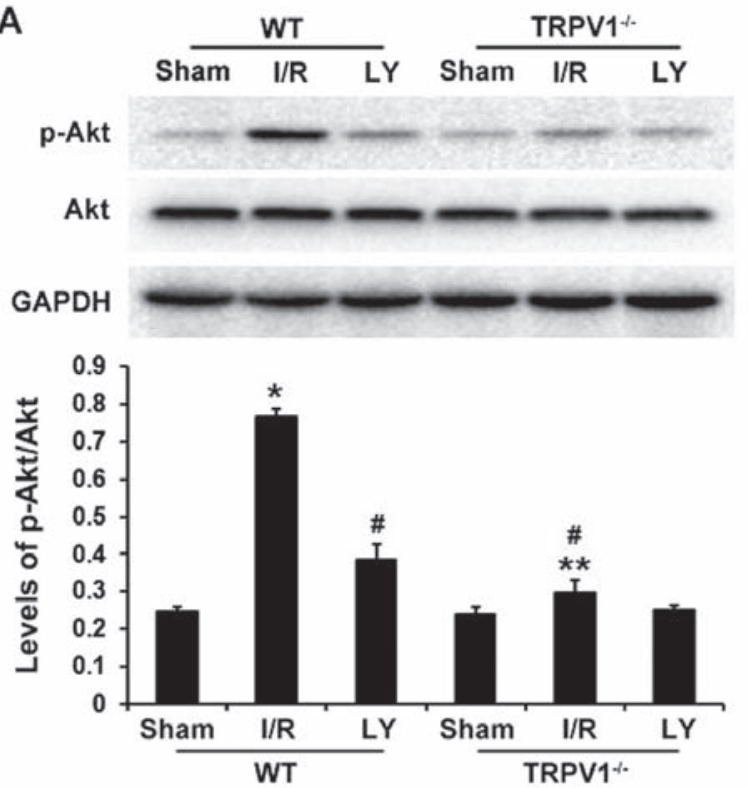

B
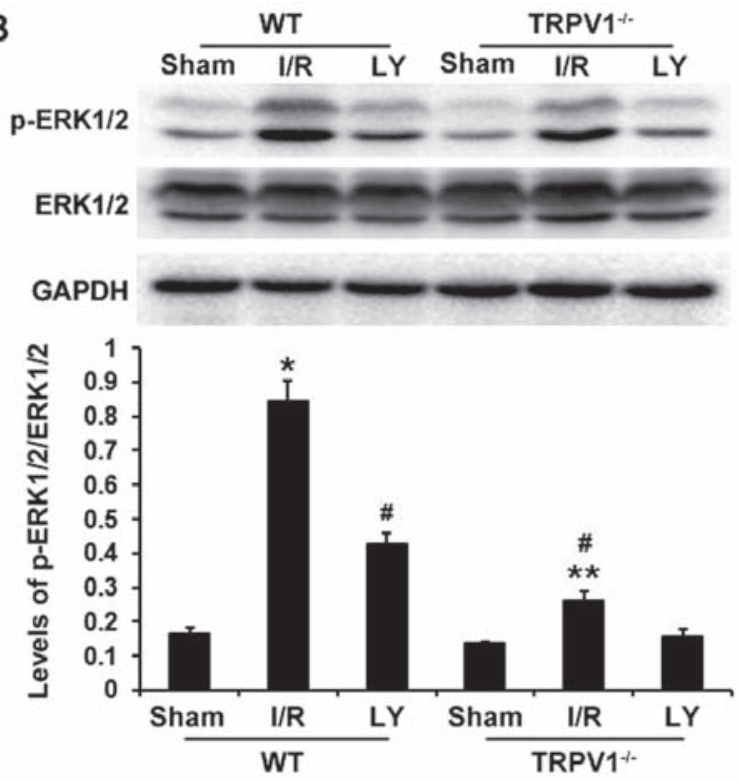

Figure 4. Phosphorylation of Akt and ERK1/2 following I/R. (A) Protein expression levels of p-Akt and total Akt, and (B) p-ERK1/2 and total ERK1/2 were assessed by western blotting with specific antibodies. Protein signals were semi-quantified by densitometry, and relative levels are presented in graphs. Data are presented as the means \pm standard deviation of three independent experiments. ${ }^{*} \mathrm{P}<0.05$ vs. the WT Sham group; ${ }^{* *} \mathrm{P}<0.05$ vs. the TRPV ${ }^{-/}$Sham group; ${ }^{\text {"P }}<0.01$ vs. the WT I/R group. Akt, protein kinase B; ERK1/2, extracellular signal-regulated protein kinase 1/2; I/R, ischemia/reperfusion; LY, LY294002; p-, phosphorylated; TRPV1 ${ }^{-/}$, transient receptor potential vanilloid 1 knockout; WT, wild-type.
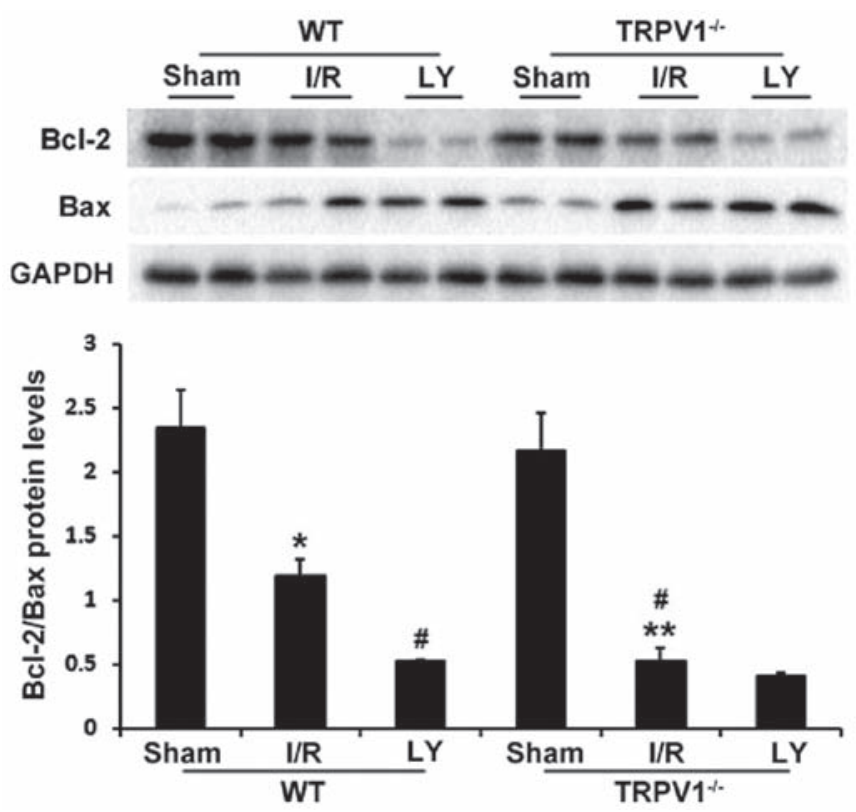

Figure 5. Bcl-2/Bax ratio following I/R. Bcl-2 and Bax protein levels were determined by western blot analysis. Data are presented as the means \pm standard deviation of three independent experiments. "P $<0.05$ vs. the WT Sham group; ${ }^{* *} \mathrm{P}<0.05$ vs. the TRPV $1{ }^{-/}$Sham group; ${ }^{*} \mathrm{P}<0.01$ vs. the WT I/R group. Bax, Bcl-2-associated X protein; Bcl-2, B-cell lymphoma 2; I/R, ischemia/reperfusion; LY, LY294002; p-, phosphorylated; TRPV1 ${ }^{-/}$, transient receptor potential vanilloid 1 knockout; WT, wild-type.

be activated by numerous metabolites that are accumulated during myocardial ischemia (12). Prior induction of TRPV1 may confer a benefit to the myocardium against further severe damage. This concept is supported by evidence that suggests that short episodes of sub-lethal ischemia may induce ischemic preconditioning, and that TRPV1 knockout abrogates the effects of ischemic preconditioning (30). In addition, TRPV1 activation promotes recovery of cardiac systolic/diastolic function during I/R (21). Apoptosis is a type of programmed cell death, which significantly contributes to myocardial I/R injury $(9,10)$; therefore, inhibition of myocardial cell apoptosis may prevent cell loss and attenuate cardiac injury during myocardial I/R (11). Apoptosis-associated proteins, including Bcl-2 and Bax serve pivotal roles in apoptosis $(28,29)$. In particular, apoptosis is regulated by the ratio of $\mathrm{Bcl}-2$ and Bax protein expression $(31,32)$. Previous studies have indicated that TRPV1 is involved in the regulation of apoptosis (22,33-35). Capsaicin has been reported to significantly reduce reperfusion-induced liver injury by reducing apoptosis due to activation of TRPV1 (34). Therefore, the present study investigated the role of TRPV1 in myocardial apoptosis during $\mathrm{I} / \mathrm{R}$. The results demonstrated that the Bcl-2/Bax ratio was significantly reduced in TRPV $1^{-/}$compared with WT hearts following I/R. Furthermore, I/R increased the percentage of TUNEL-positive cells and infarct size in TRPV1 ${ }^{-/}$hearts compared with in WT hearts. These findings suggested that TRPV1 activation protects cardiomyocytes from I/R injury by suppressing myocardial apoptosis. Although cardiac function was not assessed in the present study, our previous study demonstrated that TRPV1 deficiency results in increased mortality, aggravated inflammatory response, enhanced cardiac fibrosis and exaggerated progression of LV remodeling 7 days after myocardial infarction (36). However, further studies are required to investigate the role of TRPV1 in regulating cardiac function following $\mathrm{I} / \mathrm{R}$ in vivo.

Previous studies have revealed that capsaicin activates the PI3K/Akt and ERK1/2 pathways in dorsal root ganglion neurons (37) and human HepG2 cells (38) through activation of the capsaicin receptor TRPV1. The PI3K/Akt and ERK1/2 signaling pathways, when specifically activated at the time of 
myocardial reperfusion, may inhibit cardiomyocyte apoptosis and attenuate I/R injury through targeting downstream molecules, including Bcl-2 and Bax $(39,40)$. Therefore, the present study investigated the role of TRPV1 in phosphorylation of Akt and ERK1/2 in hearts subjected to I/R. The results indicated that the ratios of p-AKT/AKT and p-ERK1/2/ERK1/2 were upregulated in TRPV1 ${ }^{-/-}$and WT hearts following I/R compared with in the sham groups. In addition, the ratios of p-AKT/AKT and p-ERK1/2/ERK1/2 were lower in TRPV1 ${ }^{-/}$hearts compared with in WT hearts. Notably, treatment with LY294002 decreased $\mathrm{Bcl}-2 / \mathrm{Bax}$ ratio, and increased infarct size and TUNEL-positive cardiomyocytes in WT but not in TRPV1 $1^{-/}$hearts. These results suggested that TRPV1 may inhibit I/R-induced cardiomyocyte apoptosis via PI3K/Akt activation. In addition, treatment with LY294002 significantly inhibited p-ERK1/2 levels in WT but not $\mathrm{TRPV}^{-{ }^{-}}$hearts following I/R. Previous evidence has suggested that PI3K inhibition suppresses ERK1/2 activation induced by capsaicin and nerve growth factor in primary sensory dorsal root ganglion neurons (41), which is supported by the present study. However, in a previous study, PI3K has been reported to inhibit, rather than increase, ERK1/2 activation (42). It has been suggested that the ability of PI3K inhibitors to suppress ERK1/2 activation depends on cell type, the type of stimuli and the strength of signals $(43,44)$. In the present study, PI3K inhibition decreased I/R-induced ERK1/2 activation in WT mice, thus suggesting that ERK1/2 activation is PI3K-dependent. Further studies are required to explore the precise role of the ERK1/2 signaling pathway in TRPV1-induced cardiac protection.

As an ex vivo model, the Langendorff preparation has its limitations. For example, the isolated and perfused heart is denervated and its performance is not regulated by neurohumoral factors. In addition, crystalloid-perfused hearts are prone to tissue edema, which has a negative impact on cardiac function, particularly in I/R study protocols $>2 \mathrm{~h}$, which is not the case in the present study. However, the preparation is simple, reproducible and enables the study of the heart without other organ systems, which may confound physiological assessment. Due to these advantages, the Langendorff model has been used for $>100$ years to generate insightful data.

In conclusion, the present study demonstrated that TRPV1 may exert anti-apoptotic effects against myocardial I/R injury via PI3K/Akt signaling activation in isolated mouse hearts. These data suggested that TRPV1 may be considered a potential target for pharmacological intervention to reduce cardiac damage and improve clinical outcomes following cardiac I/R.

\section{Acknowledgements}

The present study was funded by the National Natural Science Foundation of China (grant nos. 81170188 and 30971212), the Natural Science Foundation of Chongqing (grant no. CSCT2009BB5069) and the National Key Subject Construction Project (grant no. 2011170).

\section{References}

1. Bolli R, Becker L, Gross G, Mentzer R Jr, Balshaw D and Lathrop DA; NHLBI Working Group on the Translation of Therapies for Protecting the Heart from Ischemia: Myocardial protection at a crossroads: The need for translation into clinical therapy. Circ Res 95: 125-134, 2004.
2. Sanada S, Komuro I and Kitakaze M: Pathophysiology of myocardial reperfusion injury: Preconditioning, postconditioning, and translational aspects of protective measures. Am J Physiol Heart Circ Physiol 301: H1723-H1741, 2011.

3. Hausenloy DJ and Yellon DM: Myocardial ischemia-reperfusion injury: A neglected therapeutic target. J Clin Invest 123: 92-100, 2013.

4. Silber S, Albertsson P, Avilés FF, Camici PG, Colombo A, Hamm C, Jørgensen E, Marco J, Nordrehaug JE, Ruzyllo W, et al; Guidelines for percutaneous coronary interventions. The Task Force for Percutaneous Coronary Interventions of the European Society of Cardiology. Eur Heart J 26: 804-847, 2005.

5. Steg PG, James SK, Atar D, Badano LP, Blömstrom-Lundqvist C, Borger MA, Di Mario C, Dickstein K, Ducrocq G, Fernandez-Aviles F, et al; Task Force on the management of ST-segment elevation acute myocardial infarction of the European Society of Cardiology (ESC): ESC Guidelines for the management of acute myocardial infarction in patients presenting with ST-segment elevation. Eur Heart J 33: 2569-2619, 2012.

6. Ibáñez B, Heusch G, Ovize M and Van de Werf F: Evolving therapies for myocardial ischemia/reperfusion injury. J Am Coll Cardiol 65: 1454-1471, 2015.

7. Yellon DM and Hausenloy DJ: Myocardial reperfusion injury. N Engl J Med 357: 1121-1135, 2007.

8. Zhang Y and Ren J: Targeting autophagy for the therapeutic application of histone deacetylase inhibitors in ischemia/reperfusion heart injury. Circulation 129: 1088-1091, 2014.

9. Tao J, Zhu W, Li Y, Xin P, Li J, Liu M, Li J, Redington AN and Wei M: Apelin-13 protects the heart against ischemia-reperfusion injury through inhibition of ER-dependent apoptotic pathways in a time-dependent fashion. Am J Physiol Heart Circ Physiol 301: H1471-H1486, 2011.

10. Konstantinidis K, Whelan RS and Kitsis RN: Mechanisms of cell death in heart disease. Arterioscler Thromb Vasc Biol 32: 1552-1562, 2012.

11. Song JQ, Teng X, Cai Y, Tang CS and Qi YF: Activation of Akt/GSK-3beta signaling pathway is involved in intermedin(1-53) protection against myocardial apoptosis induced by ischemia/reperfusion. Apoptosis 14: 1061-1069, 2009.

12. Pan HL and Chen SR: Sensing tissue ischemia: Another new function for capsaicin receptors? Circulation 110: 1826-1831, 2004.

13. Szallasi A and Blumberg PM: Vanilloid (Capsaicin) receptors and mechanisms. Pharmacol Rev 51: 159-212, 1999.

14. Caterina MJ, Schumacher MA, Tominaga M, Rosen TA, Levine JD and Julius D: The capsaicin receptor: A heat-activated ion channel in the pain pathway. Nature 389: 816-824, 1997.

15. Caterina MJ, Leffler A, Malmberg AB, Martin WJ, Trafton J, Petersen-Zeitz KR, Koltzenburg M, Basbaum AI and Julius D: Impaired nociception and pain sensation in mice lacking the capsaicin receptor. Science 288: 306-313, 2000.

16. Davis JB, Gray J, Gunthorpe MJ, Hatcher JP, Davey PT, Overend P, Harries MH, Latcham J, Clapham C, Atkinson K, et al: Vanilloid receptor-1 is essential for inflammatory thermal hyperalgesia. Nature 405: 183-187, 2000.

17. Zahner MR, Li DP, Chen SR and Pan HL: Cardiac vanilloid receptor 1-expressing afferent nerves and their role in the cardiogenic sympathetic reflex in rats. J Physiol 551: 515-523, 2003.

18. Bolli RandLatif A: No pain, no gain: the useful function of angina. Circulation 112: 3541-3543, 2005.

19. Sexton A, McDonald M, Cayla C, Thiemermann C and Ahluwalia A: 12-Lipoxygenase-derived eicosanoids protect against myocardial ischemia/reperfusion injury via activation of neuronal TRPV1. FASEB J 21: 2695-2703, 2007.

20. Rang WQ, Du YH, Hu CP, Ye F, Xu KP, Peng J, Deng HW and $\mathrm{Li}$ YJ: Protective effects of evodiamine on myocardial ischemia-reperfusion injury in rats. Planta Med 70: 1140-1143, 2004.

21. Wang L and Wang DH: TRPV1 gene knockout impairs postischemic recovery in isolated perfused heart in mice. Circulation 112: 3617-3623, 2005.

22. Dai Z, Xiao J, Liu SY, Cui L, Hu GY and Jiang DJ: Rutaecarpine inhibits hypoxia/reoxygenation-induced apoptosis in rat hippocampal neurons. Neuropharmacology 55: 1307-1312, 2008.

23. Hausenloy DJ and Yellon DM: Reperfusion injury salvage kinase signalling: Taking a RISK for cardioprotection. Heart Fail Rev 12: 217-234, 2007.

24. Bucciarelli LG, Ananthakrishnan R, Hwang YC, Kaneko M, Song F, Sell DR, Strauch C, Monnier VM, Yan SF, Schmidt AM, et al: RAGE and modulation of ischemic injury in the diabetic myocardium. Diabetes 57: 1941-1951, 2008. 
25. Cross TG, Scheel-Toellner D, Henriquez NV, Deacon E, Salmon M and Lord JM: Serine/threonine protein kinases and apoptosis. Exp Cell Res 256: 34-41, 2000.

26. Council N: Guide for the care and use of laboratory animals: Eighth edition. Guide for the Care \& Use of Laboratory Animals. 327: 963-965, 2011.

27. Rahman S, Li J, Bopassa JC, Umar S, Iorga A, Partownavid P and Eghbali M: Phosphorylation of GSK-3 $\beta$ mediates intralipidinduced cardioprotection against ischemia/reperfusion injury. Anesthesiology 115: 242-253, 2011.

28. Childs AC, Phaneuf SL, Dirks AJ,Phillips T and Leeuwenburgh C: Doxorubicin treatment in vivo causes cytochrome $\mathrm{C}$ release and cardiomyocyte apoptosis, as well as increased mitochondrial efficiency, superoxide dismutase activity, and $\mathrm{Bcl}-2$ :Bax ratio. Cancer Res 62: 4592-4598, 2002.

29. Green DR and Reed JC: Mitochondria and apoptosis. Science 281: 1309-1312, 1998

30. Zhong B and Wang DH: TRPV1 gene knockout impairs preconditioning protection against myocardial injury in isolated perfused hearts in mice. Am J Physiol Heart Circ Physiol 293: H1791-H1798, 2007.

31. Maulik N, Engelman RM, Rousou JA, Flack JE III, Deaton D and Das DK: Ischemic preconditioning reduces apoptosis by upregulating anti-death gene Bcl-2. Circulation 100 (Suppl 19): II369-II375, 1999.

32. Patel JR and Brewer GJ: Age-related differences in NFkappaB translocation and $\mathrm{Bcl}-2 / \mathrm{Bax}$ ratio caused by TNFalpha and Abeta42 promote survival in middle-age neurons and death in old neurons. Exp Neurol 213: 93-100, 2008.

33. Costa MA, Fonseca BM, Keating E, Teixeira NA and Correia-da-Silva G: Transient receptor potential vanilloid 1 is expressed in human cytotrophoblasts: Induction of cell apoptosis and impairment of syncytialization. Int J Biochem Cell Biol 57: 177-185, 2014.

34. Harada N, Okajima K, Kurihara H and Nakagata N: Stimulation of sensory neurons by capsaicin increases tissue levels of IGF-I, thereby reducing reperfusion-induced apoptosis in mice. Neuropharmacology 52: 1303-1311, 2007.

35. Sun Z, Han J, Zhao W, Zhang Y, Wang S, Ye L, Liu T and Zheng L: TRPV1 activation exacerbates hypoxia/reoxygenation-induced apoptosis in $\mathrm{H} 9 \mathrm{C} 2$ cells via calcium overload and mitochondrial dysfunction. Int J Mol Sci 15: 18362-18380, 2014.
36. Huang W, Rubinstein J, Prieto AR, Thang LV and Wang DH: Transient receptor potential vanilloid gene deletion exacerbates inflammation and atypical cardiac remodeling after myocardial infarction. Hypertension 53: 243-250, 2009.

37. Tang HB and Nakata Y: The activation of transient receptor potential vanilloid receptor subtype 1 by capsaicin without extracellular $\mathrm{Ca}^{2+}$ is involved in the mechanism of distinct substance $\mathrm{P}$ release in cultured rat dorsal root ganglion neurons. Naunyn Schmiedebergs Arch Pharmacol 377: 325-332, 2008.

38. Joung EJ, Li MH, Lee HG, Somparn N, Jung YS, Na HK, Kim SH, Cha YN and Surh YJ: Capsaicin induces heme oxygenase-1 expression in HepG2 cells via activation of PI3K-Nrf2 signaling: $\mathrm{NAD}(\mathrm{P}) \mathrm{H}$ :quinone oxidoreductase as a potential target. Antioxid Redox Signal 9: 2087-2098, 2007.

39. Chen S, Liu J, Liu X, Fu Y, Zhang M, Lin Q, Zhu J, Mai L, Shan Z, Yu X, et al: Panax notoginseng saponins inhibit ischemia-induced apoptosis by activating PI3K/Akt pathway in cardiomyocytes. J Ethnopharmacol 137: 263-270, 2011.

40. Weston CR, Balmanno K, Chalmers C, Hadfield K, Molton SA, Ley R, Wagner EF and Cook SJ: Activation of ERK1/2 by deltaRaf-1:ER* represses Bim expression independently of the JNK or PI3K pathways. Oncogene 22: 1281-1293, 2003.

41. Zhuang ZY, Xu H, Clapham DE and Ji RR: Phosphatidylinositol 3-kinase activates ERK in primary sensory neurons and mediates inflammatory heat hyperalgesia through TRPV1 sensitization. J Neurosci 24: 8300-8309, 2004.

42. Rommel C, Clarke BA, Zimmermann S, Nuñez L, Rossman R, Reid K, Moelling K, Yancopoulos GD and Glass DJ: Differentiation stage-specific inhibition of the Raf-MEK-ERK pathway by Akt. Science 286: 1738-1741, 1999.

43. Duckworth BC and Cantley LC: Conditional inhibition of the mitogen-activated protein kinase cascade by wortmannin. Dependence on signal strength. J Biol Chem 272: 27665-27670, 1997.

44. Wennström S and Downward J: Role of phosphoinositide 3-kinase in activation of ras and mitogen-activated protein kinase by epidermal growth factor. Mol Cell Biol 19: 4279-4288, 1999. 